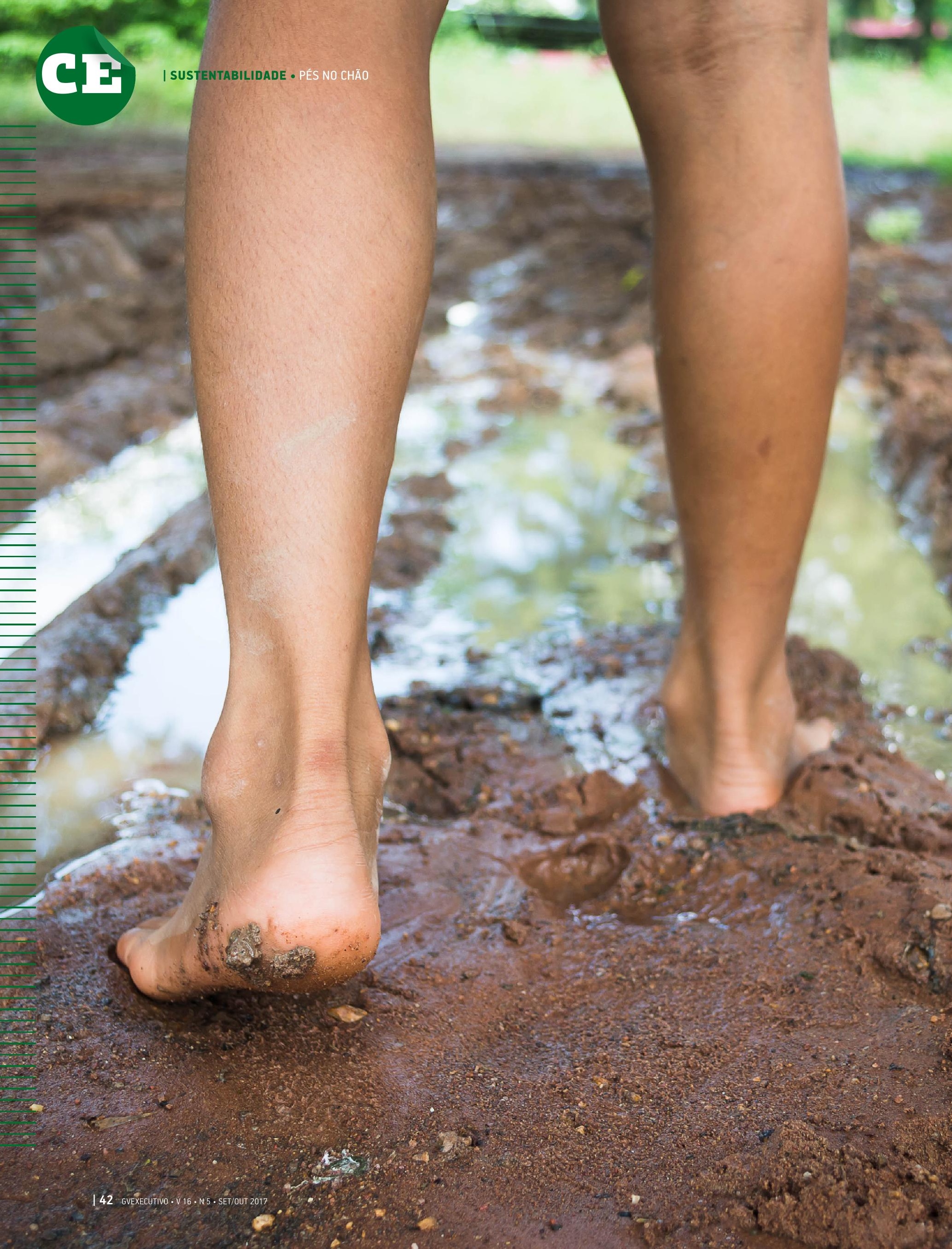




\section{PÉS NO CHÃO}

\section{A governança territorial vem ganhando força ao gerar oportunidades para o desenvolvimento local no contexto da instalação de grandes obras no país e no mundo.}

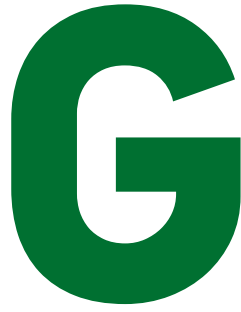

randes projetos de infraestrutura - como hidrelétricas e complexos logísticos - e indústrias extrativas têm o potencial de contribuir significativamente para o desenvolvimento e a redução da pobreza em países em desenvolvimento. No entanto, não é incomum que as oportunidades não sejam convertidas em benefícios reais, especialmente nos territórios que hospedam tais obras. Em cenários ainda menos animadores, a implementação de projetos de infraestrutura pode fazer emergir novas questões sociais e ambientais ou agravá-las, tendo em vista o rápido aumento da migração, a urbanização acelerada, a provisão insuficiente de serviços públicos, a inflação nas regiões onde os projetos são instalados, bem como as pressões sobre áreas protegidas e populações tradicionais.

Estudos sobre os efeitos de projetos de infraestrutura indicam que eles vêm sendo subestimados historicamente. Questões como o deslocamento compulsório de populações locais e a perda de seus meios de subsistência, a redução da biodiversidade e o aumento do desmatamento ainda são desafios para o desenvolvimento sustentável nesse contexto.

A descoordenação entre os impactos na qualidade de vida local e a injeção de recursos financeiros nas regiões impactadas também é um aspecto que vale ser destacado. Enquanto os impactos ambientais e socioeconômicos são percebidos desde o anúncio do projeto de infraestrutura (a exemplo da sobrecarga nos equipamentos públicos), os recursos financeiros, sob a forma de impostos e royalties, só chegarão aos territórios mais tarde, após o início da operação do empreendimento.

Além disso, a celeridade nas obras nos canteiros não é acompanhada pela mesma agilidade nas infraestruturas necessárias para mitigação e compensação social e ambiental. No Brasil, é recorrente a construção e a operação de hospitais após o pico migratório em regiões que recebem grandes empreendimentos. Na implantação da usina hidrelétrica de Belo Monte, no Pará, a rede de esgoto instalada pelo empreendedor, como condicionante do licenciamento ambiental, não foi acompanhada por sua ligação nas casas, tornando, 


\section{Empreendimentos que levam em consideração a responsabilidade social e ambiental têm mais chance de sucesso, pois apresentam custos inferiores, melhor perfil de risco e resultados financeiros superiores.}

durante um longo período, o investimento de mais de $\mathrm{R} \$ 300$ milhões inefetivo sob o ponto de vista da população local. Ou seja, em um contexto de rápidas transformações sociais locais, a demanda de articulação entre empreendedores e poder público para mais efetividade das ações ainda é um desafio a ser superado.

Os impactos negativos dessas dinâmicas podem levar diversas consequências às operações de uma empresa, como paradas operacionais, judicializações e danos reputacionais. É clara a necessidade de referências para elevar a barreira em termos de padrões ambientais e sociais em regiões com carências nessas frentes - em geral, territórios-alvo de grandes projetos -, bem como uma oportunidade de mostrar que empreendimentos que levam em consideração a responsabilidade social e ambiental têm maior chance de sucesso, com custos mais baixos, melhor perfil de risco e, consequentemente, melhores resultados financeiros.

\section{DIRETRIZES PARA UMA}

\section{INFRAESTRUTURA SUSTENTÁVEL}

Diferentes iniciativas voltadas à elaboração e implementação de diretrizes para projetos de infraestrutura estão em andamento no mundo. De maneira geral, é possível dizer que elas são orientadas com base em duas abordagens distintas. A primeira tem foco no projeto, cujo objetivo é a melhora de seu desempenho socioambiental e engloba iniciativas como os padrões de desempenho da International Finance Corporation (IFC), do Grupo Banco Mundial, os princípios do Equador, a plataforma Envision, da Universidade de Harvard, entre outras. A segunda está relacionada ao âmbito nacional ou supranacional, com diretrizes e padrões que contemplam uma abordagem mais estratégica e global para as políticas públicas e para o planejamento governamental. É o caso das salvaguardas do Banco Mundial e de critérios socioambientais dos bancos nacionais de desenvolvimento.
No entanto, os impactos cumulativos e as especificidades locais não são suficientemente endereçados nem por diretrizes específicas do projeto nem por diretrizes nacionais ou regionais. De um lado, empreendedores de grandes obras, com visão e abordagem voltadas ao projeto, não são capazes de, isoladamente, resolver problemas sistêmicos, tornando limitada a sua contribuição para o desenvolvimento sustentável. Por outro lado, governos nacionais geralmente não alcançam, no desenho de suas políticas, as especificidades regionais, o que frequentemente leva à pouca aderência $\mathrm{e}$ efetividade no nível local.

Grandes projetos de infraestrutura e mineração geralmente são planejados, implementados e medidos de acordo com as expectativas criadas por determinados setores da economia ou políticas macroeconômicas nacionais. Quase não permanecem conexões com demandas locais e regionais dos territórios que hospedam tais empreendimentos. O resultado, muitas vezes, é a perda de oportunidades socioeconômicas, restrições sobre os modos de vida e o uso dos recursos naturais, condições elementares para o desenvolvimento humano. Em casos extremos, tal desconexão pode até potencializar as chances de violação de direitos.

\section{ABORDAGEM TERRITORIAL}

Falta uma abordagem de análise da implementação da infraestrutura que aponte para problemas no âmbito territorial. Entre os exemplos das questões que podem ser identificadas nesse contexto estão: a emergência ou o aprofundamento de questões sociais; a falta de planejamento; o descasamento entre os tempos do projeto de infraestrutura e do percurso do desenvolvimento local; a necessidade de fortalecimento de capacidades locais; os desajustes entre geração de receita e necessidades locais; a ausência de participação local; e, por fim, papéis e responsabilidades pouco claros das empresas e das políticas públicas. 
A iniciativa Grandes obras na Amazônia: aprendizados e diretrizes, liderada pelo Centro de Estudos em Sustentabilidade da FGV EAESP (GVces) e pela International Finance Corporation (IFC), é resultado de dois anos de consulta a mais de 130 organizações e da sistematização das lições aprendidas sobre políticas públicas e práticas empresariais no contexto da instalação e operação de grandes obras na Amazônia brasileira.

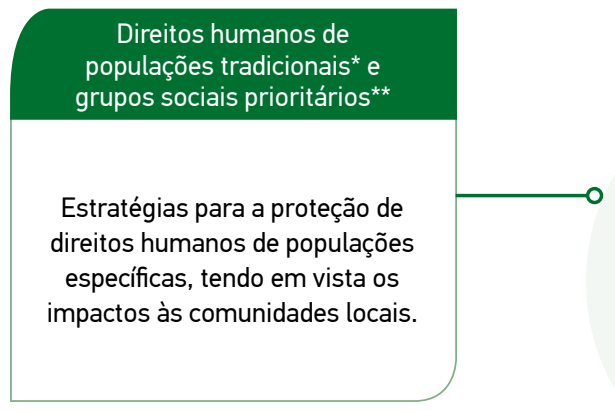

Direitos humanos de populações tradicionais* grupos sociais prioritários*

Estratégias para a proteção de direitos humanos de populações específicas, tendo em vista os impactos às comunidades locais.

\section{GRANDES OBRAS NA AMAZÔNIA: APRENDIZADOS E DIRETRIZES}

\section{Planejamento e}

ordenamento territorial

Preparação de territórios com base nas capacidades e fragilidades do contexto de grandes obras e aprimoramento da coordenação de políticas públicas e contrapartidas dos empreendedores para a promoção de legados de longo prazo.
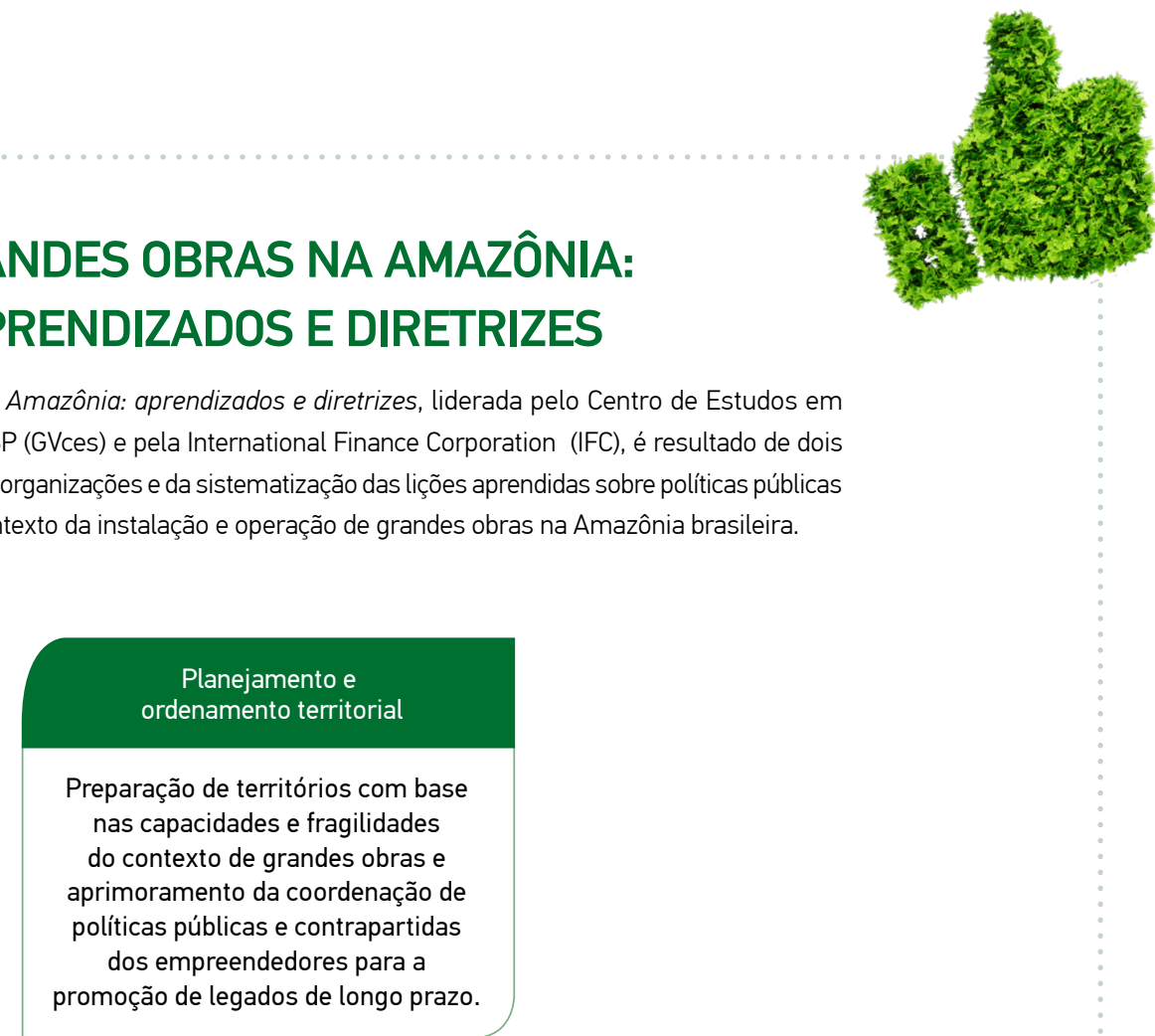
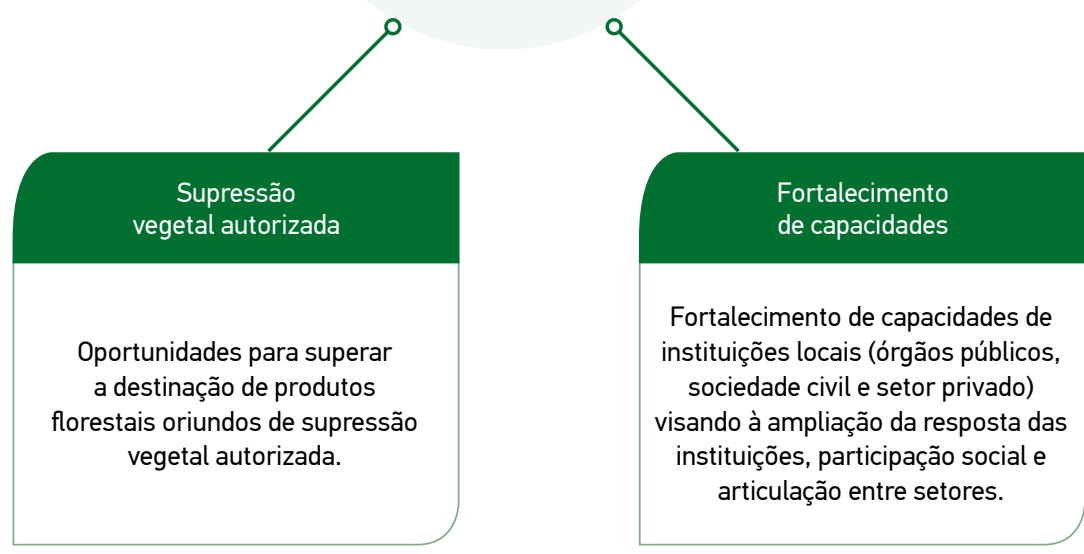


\section{O QUE É GOVERNANÇA?}

O Relatório de Desenvolvimento Global do Banco Mundial de 2017 traz que governança é o processo por meio do qual o Estado e os grupos não estatais interagem para formular e implementar políticas, trabalhando sob um conjunto de normas formais e informais que determinam a interação entre diferentes agentes da sociedade em prol de objetivos comuns. 0 relatório demonstra como políticas formuladas e implementadas em ambiente de participação social têm mais chances de serem efetivas.

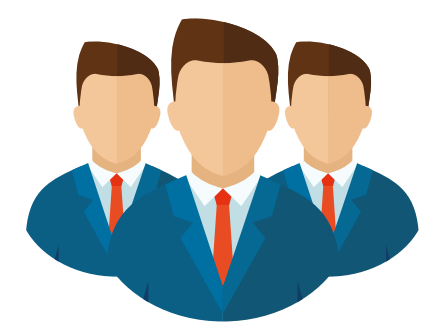

Além disso, geralmente obras de infraestrutura compreendem um conjunto de projetos, não um projeto único. A combinação de ativos logísticos (como estradas e portos), usinas hidrelétricas e/ou indústrias extrativas em um mesmo território são comuns, o que implica impactos cumulativos e sinérgicos que merecem atenção redobrada do ponto de vista das estratégias de mitigação e compensação social. A discussão global sobre governança revela que a complexidade dos desafios atuais já não pode mais ser endereçada apenas pela ação unilateral de governos ou de determinados grupos de interesse, nem ter uma abordagem top-down. Nos últimos anos, experiências de implementação de projetos de infraestrutura de grande escala e investimentos em mineração, seja uma usina hidrelétrica na floresta amazônica, um projeto de mineração no Peru ou um estádio de futebol em uma cidade grande, mostraram a complexa e intrínseca dinâmica de relações sociais, institucionais, econômicas e culturais entre empresas e demais atores do entorno de suas operações. É a evidência prática do conceito de território, consagrado como uma construção social e política derivada da ação coletiva de grupos, interesses e instituições na intrincada rede de relações entre um espaço geográfico e o que acontece nele. Essa relação é fundamental para que as empresas ganhem a licença social para operar, tornando-se parte dos territórios que ocupam e das cadeias de valor que desenvolvem. Carências locais estruturantes ou influências sociais e ambientais negativas das operações empresariais têm reflexos diretos em riscos associados aos negócios e demandam o desenvolvimento de capacidade de interlocução, diálogo, negociação e planejamento compartilhado.

Se é no território que as relações ocorrem, essas dinâmicas podem encontrar mais efetividade em uma abordagem de governança territorial. É preciso criar condições favoráveis para a organização da multiplicidade de relações que caracteriza as interações entre atores e interesses para a

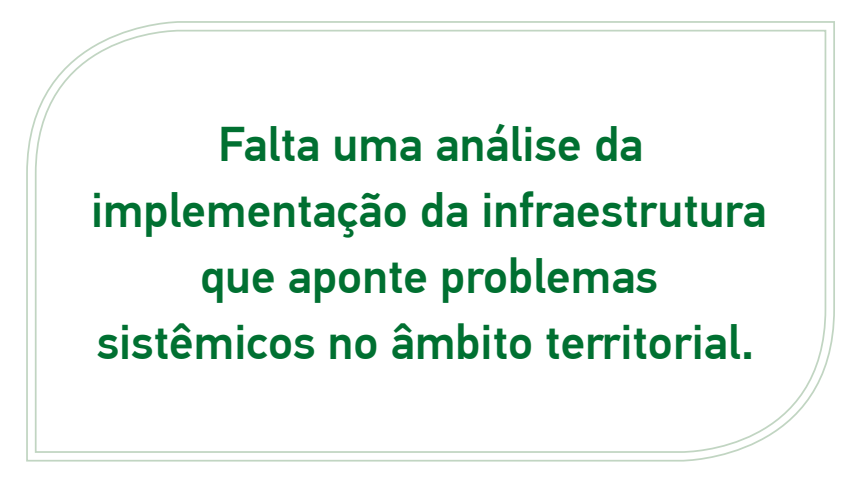

construção de uma visão compartilhada territorial. Por meio da cooperação e da coordenação vertical e horizontal pode-se alcançar coesão e bens comuns.

Assim, a incorporação dessa abordagem nas políticas e práticas territoriais pode potencializar a capacidade do setor empresarial em atuar com essa visão mais integrada, processo que leva a um gerenciamento de risco muito mais efetivo. Estudos em todo o mundo demonstram que os custos em relação aos conflitos com as populações locais têm aumentado e que as empresas ainda não conhecem as melhores ferramentas para evitá-los. A combinação entre diálogo, participação social e governança parece ser a chave para uma abordagem que reduz riscos e oferece mais condições para o real desenvolvimento local nos territórios impactados por grandes obras.

\footnotetext{
PARA SABER MAIS:

Centro de Estudos em Sustentabilidade da Fundação Getulio Vargas (GVces) e International Finance Corporation (IFC). Grandes obras na Amazônia: aprendizados e diretrizes, 2017. Simin Davoudi, Nick Evans, Francesca Governa e Marco Santangelo. Territorial governance in the making. Approaches, methodologies, practices. Boletín de la A.G.E. n. 46, 2008.

DANIELA GOMES PINTO > Coordenadora do Programa Desenvolvimento Local do GVces da FGV EAESP > daniela.gomes@fgv.br

LÍVIA MENEZES PAGOTTO > Pesquisadora do GVces e doutoranda em Administração Pública e Governo pela FGV EAESP > livia.pagotto@fgv.br
} 